\title{
The Spatial Impact of Financial Support on Cultural Creativity Industry Agglomeration _An Empirical Analysis Based on Provincial Data
}

\author{
Yang Xueqi $i^{1, a^{*}}$ \\ ${ }^{1}$ School of Economics and Commerce, South China University of Technology, Guangzhou, \\ Guangdong, China
}

ayangyangyangxq@163.com

\begin{abstract}
Keywords: Financial support, Cultural creativity industry, Agglomeration, Spatial impact.
\end{abstract}
\begin{abstract}
Cultural creativity industry has gradually become a pillar industry of China's national economy, its rapid development and concentration can not be separated from the support of financial industry and financial policy. In this paper, spatial factors are added creatively, and the current and inter-temporal models of spatial measurement are constructed to study the spatial impact of financial support on cultural creativity industry agglomeration. The results show that, in the impact of financial development on cultural creativity industry agglomeration, the indirect financing of bank credit plays a relatively large role, the stock market has not fully play its supporting role.
\end{abstract}

\section{金融支持对文化创意产业集聚的空间影响 \\ 一一基于省域数据的实证分析}

\author{
杨雪琪 $1, a^{*}$
}

1华南理工大学经济与贸易学院, 广州, 广东, 中国

ayangyangyangxq@163.com

关键词：金融支持; 文化创意产业; 集聚;空间影响

中文摘要. 文化创意产业已经逐渐成为我国国民经济的支柱性产业, 其快速发展和集聚离不 开金融产业和金融政策的支持。本文创新性地加入空间因素, 构建空间计量当期和跨期模型, 实证研究我国省域金融支持对文化创意产业集聚的空间影响。结果表明，在金融体系发展对 文化创意产业集聚的影响中, 银行信货为主的间接融资发挥了比较大的作用, 股票市场并未 充分发挥其支持作用。

\section{1. 引言}

2010 年我国九部门联合下发《关于金融支持文化产业振兴和发展繁荣的指导意见》的文 件，提出改进和创新文化创意产业的金融支持服务，为我国文化创意产业的集聚发展提供了 新的思路。金融业的发展可以为产业集聚提供资金, 同时还能激发企业家才干，从而推动产 业集聚的发展。文化创意产业作为我国国民经济的重点布局产业, 其集聚水平的提高自然离 不开金融产业和金融政策的支持。研究金融体系的发展对文化创意产业集聚的支持作用，可 以促进我国文化创意产业与金融产业的强化对接, 加大我国文化创意产业集聚的金融支持力 度，从而培育我国经济新的增长点。基于已有文献，本文创新性地加入空间因素，构建空间 计量当期和跨期模型，实证研究我国省域金融支持对文化创意产业集聚的空间影响，从而为 
利用金融体系的深化发展推动我国文化创意产业集聚水平的提高提供政策建议。

\section{2. 我国金融发展支持文化创意产业集聚的实证分析}

\section{1 指标选取}

\subsection{1 文化创意产业集聚指标}

选取各省域文化创意产业就业区位商(cLQ)来对我国 31 个省域的文化创意产业集聚程度 进行测量。

\subsection{2 金融体系发展指标}

结合现有文献研究，金融系统对文化创意产业集聚的支持作用主要体现在保险市场的风 险保障、银行类金融机构的商业信贷和资本市场的股权融资三个方面上。考虑到数据可得性， 本文选取我国各省份的保费收入占全国比重(insur)、各省份金融机构贷款余额占 GDP 比重 (bank)、各省份股票市价总值占全国比重(secur)来表示我国金融发展水平。

\subsection{3 控制变量指标}

除了金融体系发展的支持作用，文化创意产业集聚也可能受到非金融因素的影响。地区 文化创意企业数量多会使文化创意企业间的前后向联系加强, 地区对文化创意产品的需求随 之增大, 从而吸引更多企业的加入, 产生产业集聚的向心力, 因此本文选用各省份文化及相 关产业法人单位数占全国的比重(firm)指标来表示文化创意企业之间的前后向关联，从而考察 其对文化创意产业集聚的影响程度。此外, 各地区文化创意产业集聚离不开政府的财政政策 的支持，本文用各省份文化体育与传媒支出与全国均值之比(fs)来表示。

\section{2 数据来源}

本文就业区位商的数据来源于 2009 和 2015 年《中国人口和就业统计年鉴》, 保险业、银 行业和证券业数据来源于 2009 和 2015 年《中国金融年鉴》, 控制变量数据则来源于 2009 和 2015 年的《中国统计年鉴》和《中国文化及相关产业统计年鉴》。

\section{3 模型选择和构建}

\subsection{1 模型选择}

本文通过拉格朗日乘数(LM)检验来对空间误差模型和空间滞后模型进行选择。首先比较 LM-Error 和 LM-Lag 两个统计量的显著程度, 如果两者一样显著, 则对 Robust LM-Error 和 Robust LM-Lag 的显著性进行进一步比较。

表 2 LM 检验结果

\begin{tabular}{|c|c|c|}
\hline 检验 & 统计量 & P 值 \\
\hline LM-Error13 & 1.366 & 0.243 \\
\hline LM-Lag13 & 8.292 & $0.004^{* * *}$ \\
\hline Robust LM-Error13 & 0.199 & 0.655 \\
\hline Robust LM-Lag13 & 7.126 & $0.008^{* * *}$ \\
\hline LM-Error08 & 0.682 & 0.409 \\
\hline LM-Lag08 & 5.673 & $0.017^{* *}$ \\
\hline Robust LM-Error08 & 0.079 & 0.779 \\
\hline Robust LM-Lag08 & 5.069 & $0.024^{* *}$ \\
\hline
\end{tabular}

数据说明: $*$ 、**、***分别表示在 $10 \% 、 5 \% 、 1 \%$ 水平上通过显著性检验

先对以 2014 年文化创意产业修正区位商为被解释变量，以 2014 年的金融体系发展指标 和控制变量为解释变量的当期模型进行 LM 检验, 发现 LM-Lag 统计值比 LM-Error 统计值更 加显著, 进一步比较发现统计量 Robust LM-Lag(7.126)同样比统计量 Robust LM-Error(0.199) 更加显著。同时, LM-Lag 及 Robust LM-Lag 都在 1\%的水平下显著。因此对于当期模型来说， 
空间滞后模型更加适合。再对以 2014 年文化创意产业修正区位商为因变量, 以 2008 年的金 融体系发展指标和控制变量为自变量的跨期模型进行 LM 检验, 发现统计量 LM-Lag(5.673) 比统计量 LM-Error(0.682)更加显著, 同样, 统计量 Robust LM-Lag(5.069)比统计量 Robust LM-Error(0.079)更加显著。因此，空间滞后模型同样是更适合跨期模型的。

\subsection{2 模型构建}

由 LM 检验结果，本文在当期模型和跨期模型的空间回归分析中均选择空间滞后模型来 进行定量的研究, 其表达式如下, 为了消除可能存在的异方差影响, 我们对模型进行了对数 化处理。

$$
\ln c L Q_{i}=\rho W \ln c L Q_{i}+\beta_{0}+\beta_{1} \ln \text { finance }_{i}+\beta_{2} \ln \text { control }_{i}+\varepsilon_{i}
$$

在上式中， $W$ 为空间权重矩阵，表示地区间的空间相互作用，本文选用空间二分权重矩 阵。 $i$ 表示除港澳台外的我国的 31 个省市地区, $W \ln c L Q_{i}$ 为空间滞后因变量，系数 $\rho$ 为空间 滞后系数，表示本地区的文化创意产业集聚受周边地区的文化创意产业集聚的加权的影响程 度, $\varepsilon_{i}$ 为随机误差项向量。

\section{4 回归结果分析}

\subsubsection{4 年当期模型的回归分析}

表 3 当期模型的 SLM 和 OLS 回归结果

\begin{tabular}{|c|c|c|}
\hline 变量 & OLS & SLM \\
\hline $\operatorname{lninsur13}$ & 0.5264 & $0.5685^{* *}$ \\
\hline $\operatorname{lnbank13}$ & 0.6556 & $0.7866^{*}$ \\
\hline $\operatorname{lnsecur13}$ & $0.5935^{* *}$ & $0.4716^{* *}$ \\
\hline $\operatorname{lnfirm13}$ & -0.2633 & -0.3647 \\
\hline $\operatorname{lnfs13}$ & 0.2443 & 0.5184 \\
\hline constant13 & -0.3610 & -0.1734 \\
\hline W_lncLQ13 & - & $0.2421^{*}$ \\
\hline $\mathrm{R}^{2}$ & 0.8034 & 0.823 \\
\hline Log Likelihood & - & -22.1642 \\
\hline Wald test & - & $2.985^{*}$ \\
\hline
\end{tabular}

数据说明: *、**、***分别表示在 $10 \% 、 5 \% 、 1 \%$ 水平上通过显著性检验

引入空间相关性后，模型的各种检验值均得到了一定程度的改善。模型的拟合优度由原 来的 0.8034 提高到 0.823 , 反映出引入空间因素之后模型的解释力度得到了提高; 具体看, 每个变量的估计系数的显著性也都得到了提高, 并且各解释变量的估计系数没有发生显著变 化，这表明系数的估计值稳健可信; SLM 模型在 10\%的水平下通过了 Wald 检验; 在 SLM 模 型的估计结果中还可以看到文化创意产业集聚的空间自回归变量的系数 $\rho$ 的估计值为 0.2421 , 并且在 $10 \%$ 的置信水平下通过了显著性检验, 这表明邻近省份的文化创意产业集聚程度对本 省的文化创意产业集聚会产生空间溢出效应，我国 31 个省市的文化创意产业集聚存在正的空 间相关性。以上这些都有力地证明了考虑地区间空间溢出效应的空间滞后模型更加适合当期 模型的研究和分析。

当期模型金融体系发展对文化创意产业集聚的支持作用中，保险业、银行业和证券业的 估计系数都为正且显著, 表明当期金融产业的发展对文化创意产业的集聚是有一定积极作用 的。

具体来看，保险业支持变量的估计系数为 0.5685 , 在 $5 \%$ 的水平下显著，保险业对我国文 化创意产业的集聚有正向支持作用。2012 年，我国九部委联合下发了《关于金融支持文化创 意产业振兴和发展繁荣的指导意见》, 突破性地在文化创意产业的融资体系中加入了保险机制。 保险业作为金融体系中一种特殊的体制, 可以通过发挥自身的保障功能, 为文化创意产品及 服务提供一定的风险保障。同时保险业的发展还能帮助文化创意企业克服融资信用不足的缺 点, 开拓中小企业融资渠道，解决其发展的资金困难，从而为我国文化创意产业的集聚助攻。

银行业的发展增加 $1 \%$ 可以推动文化创意产业集聚增加 $0.7866 \%$ 。近年来，我国银监会及 
各省市银监局积极探索“文化金融”的道路，对银行业金融机构进行政策引导，促进其与文化 创意产业的特点形成契合, 探索和发展多样化的融资模式, 加大针对文化创意企业的有效信 贷投放力度，改革信贷产品，促进信贷产品的创新，实现金融资本与文化创意产业的对接。 同时，银行业金融机构也进一步增强特色的机构建设，做专文化创意产品和服务，从而为文 化创意企业提供更加优质的金融服务。2008 年，北京银行直接以版权质押向华谊兄弟提供 1 个亿的贷款，这开创了金融支持文化创意产业融资的一个新的历史。2010 年 7 月中国银行的 创新金融产品 “影视通宝” 开始运作, 它以影视剧版权及应收账款作为质押物, 来对文化创意 产业中的优秀影视企业提供贷款，是银行为文化创意产业发展提供的创新性金融体制。

证券业的发展同样对文化创意产业集聚有正向的推动作用。基金、股票等金融产品及一 些私募股权投资机构与文化创意企业的结合既可以为为文化创意产业提供新颖的股权融资， 又可以帮助文化创意企业防范风险，从而实现促发展和防风险的相结合的平衡进步。

在当期模型中，银行业的支持作用最大，其次是保险业，证券业在三者中的作用则最小。 具体原因可能是, 银行业在我国的起源最早, 也是在三者中发展比较成熟的, 而且银行业的 金融发展水平对文化创意产业的集聚发展的支持作用比较直接, 文化创意企业的受益面也比 较广，商业信贷融资门槛相对较低。而保险业相对于证券业起步相对也比较早，且其自身所 具有的风险保障功能可以使其与银行业金融机构合作，为商业信贷融资提供风险保障，从而 与银行业金融机构共同推进文化创意产业的集聚。证券业在我国的发展历史不过数十年之久, 目前还处于初期发展阶段, 所以对文化创意产业集聚的推动作用尚且有限, 而且我国文化创 意产业的发展也处于初级阶段, 文化创意企业大多为中小民营企业, 其中大部分企业仍处于 成长期, 尚未达到上市规模要求。但是股权融资对于文化创意产业仍有极大的吸引力, 股权 融资对文化创意产业集聚的支持作用的发挥存在着很大的潜力, 所以, 虽然目前证券业对文 化创意产业集聚的支持作用有限, 但是, 随着一些文化创意企业的发展成熟, 进而在中小板 及创业板上市融资，证券业将会对文化创意产业的集聚发展表现出不可估量的支持作用。

由控制变量的回归结果, 在当期模型中文化创意企业的前后向关联控制变量与我国文化 创意产业的集聚尚未呈现出显著的相关关系, 这可能是由于我国文化创意产业的发展仍处于 初级阶段, 文化创意市场还有待进一步发展。且政府的财政支出控制变量仅在 $20 \%$ 的水平下 显著, 究其原因可能是政府对于文化创意产业的财政支出需要一定时间的投入产出才能显现 出其效果，因此当期的政府财政支出对当期文化创意产业集聚的支持作用并不是十分明显。

2.4.2 2008-2014 年跨期模型的回归分析

表 4 跨期模型的 SLM 和 OLS 回归结果

\begin{tabular}{|c|c|c|}
\hline 变量 & OLS & SLM \\
\hline Ininsur08 & 0.2394 & 0.3146 \\
\hline Inbank08 & 0.1406 & 0.1773 \\
\hline $\operatorname{lnsecur08}$ & $0.4003^{* *}$ & $0.3812^{* * *}$ \\
\hline $\operatorname{lnfirm08}$ & 0.3880 & 0.1497 \\
\hline $\operatorname{lnfs08}$ & 0.4900 & $0.6872^{*}$ \\
\hline constant08 & -0.6663 & -0.3561 \\
\hline W $\operatorname{lncLQ08}$ & - & $0.2447 *$ \\
\hline $\mathrm{R}^{2}$ & 0.7985 & 0.821 \\
\hline Log Likelihood & - & -22.2990 \\
\hline Wald test & - & $3.540^{*}$ \\
\hline
\end{tabular}

数据说明: *、**、***分别表示在 $10 \% 、 5 \% 、 1 \%$ 水平上通过显著性检验

跨期空间滞后模型的各种检验结果相比不加入空间相关性的普通最小二乘法均得到了改 善。引入空间因素的空间滞后模型 SLM 的拟合优度提高到了 0.821 , 模型的解释力度有所提 高; 同时 SLM 模型在 10\%的水平下通过了 Wald 检验; 且相比 OLS 模型, SLM 模型各解释 变量的估计系数变得更加显著, 系数的估计结果没有发生显著变化, 估计结果稳健; 文化创 意产业集聚的空间滞后因变量的系数 $\rho$ 的估计值为 0.2447 , 通过了 $10 \%$ 水平下的显著性检验, 说明跨期模型中邻近省份的文化创意产业集聚对本省份的文化创意产业集聚存在空间溢出效 
应，我国的文化创意产业集聚存在正的空间相关性。因此，在 2008-2014 年的跨期分析中， 空间滞后模型同样是更适合的模型。

在 SLM 跨期模型的金融体系发展对文化创意产业集聚的支持作用中,保险业支持变量通 过了 $20 \%$ 置信水平下的显著性检验, 跨期模型保险业金融发展水平变量对文化创意产业集聚 的支持作用比较微弱, 究其原因可能是, 在我国, 保险业被引入到文化创意产业的融资体系 中的历史非常短, 2008 年时保险业为文化创意产业提供融资和风险保障的功能发挥刚刚起步, 仍处于萌芽状态，保险机制仅对少数比较大的文化创意企业提供帮助，例如 2006 年文化创意 企业龙头华谊兄弟为其即将海外上映的电影《夜宴》投保海外发行的保险，从而为其文化创 意产品提供风险保障, 但是大部分中小文化创意企业实力仍有限, 保险业尚未全面介入对文 化创意企业的融资。

银行业支持变量与文化创意产业集聚因变量也并没有呈现出显著的相关关系，这可能是 由于银行业金融发展水平对文化创意产业集聚存在着相对直接的支持作用，银行业金融机构 的商业信贷融资对文化创意产业的作用通常在当期即可显现出来，同时由于金融商业贷款在 文化创意产业内部企业间的分配不均衡, 导致文化创意产业内部的金融政策存在“包容性”缺 陷, 使文化创意产业中的中小和民营企业的兼并重组缺乏金融支持, 不能推动文化创意产业 的市场化投资，商业贷款的效果有限，时效较短。

证券业金融发展水平自变量的估计结果则相对显著, 其回归系数为 0.3812 , 并且通过了 $1 \%$ 水平下的显著性检验，对文化创意产业集聚存在明显的支持作用。证券业可以为文化创意 企业的发展提供股权融资，并且这类融资为企业提供的资金金额巨大且稳定，其不同于银行 的商业信贷, 具有非偿还性, 这就绝对了证券业对文化创意产业集聚的影响比较深远, 跨期 相对较长。

通过以上分析可知，在 2008-2014 年的跨期模型中，证券业对文化创意产业集聚的支持 作用最大, 保险业的支持作用相对微弱, 银行业与文化创意产业集聚没有表现出显著相关关 系。

在跨期模型的控制变量中, 文化创意企业前后向关联变量同样不显著, 这与当期模型的 估计结果一致，而财政支出变量则在 $10 \%$ 的水平下显著，其估计系数为 0.6872 , 表明 2008 年的政府文化创意产业财政支出对 2014 年的我国文化创意产业集聚存在显著正向影响, 在五 年间政府的支出经过投入产出的过程转化为了对地区文化创意企业的支持, 推动了文化创意 产业的发展和集聚。

\section{3. 结论及政策启示}

\section{1 研究结论}

在金融体系发展对文化创意产业集聚的当期影响和支持作用中，银行业的支持作用最大， 其次是保险业, 证券业的支持作用则最小。而在金融体系发展对文化创意产业集聚的跨期影 响和支持作用中, 证券业的支持作用比较显著, 保险业表现出微弱的支持作用, 而银行业的 没有明显的支持作用。

\section{2 政策启示}

本文根据研究结果提出以下政策建议。首先, 完善商业银行的信贷和服务。政府应该发 挥好银行业支持的主导地位, 更多开发和推广无形资产质押信贷的创新金融产品, 同时政府 也应出台政策适当降低贷款标准及利息, 鼓励银行积极为中小文化创意企业提供优质信贷和 服务。其次, 创新保险机构的风险保障服务。政府应鼓励保险业积极创新, 探索信用保险业 务, 使保险的资金融通功能得到发挥。最后, 加强资本市场的融资渠道。支持实力雄厚的优 质企业在我国主板上市; 成长性较好的创业型中小企业可以在创业板或者新三板培育发展; 对于发展十分成熟的文化创意企业, 还可以鼓励其在境外市场进行融资。我国的证券业对文 化创意产业集聚的支持作用仍有较大的发展潜力, 这也是今后我国金融政策的重点努力方向。 


\section{References}

[1] L. Bottazzi, Globalization and Localproxim Ity in Innovation: A Dynamic Process, European Economic Review, vol.45, pp. 731-741, 2011.

[2] Qian Shuitu, Jiang Le, The Impact of Zhejiang Regional Financial Structure on Industry Cluster-An Empirical Research Based on Panel-data, Statistic Reasearch, vol.26, pp. 62-67, 2009.

[3] Zhang Xiaodi, Wang Yongqi, Entrepreneur and Industrial Agglomeration: Coupling Effects of the Financial Markets, China Industrial Economics, vol.5, pp. 59-67, 2010.

[4] Yuan Hai, Cao peishen, Spatial Econometric Analysis of Regional Agglomeration of Chinese Cultural Industry, Statistics and Decision Making, vol.10, pp. 77-80, 2011.

[5] Ma Runping, Financial Development and Industrial Agglomeration: Based on Jiangsu Province Panel Data Analysis, Social Sciences in Ningxia,vol.3, 38-43,2012.

[6] Xiong Zhengde, The Impact of Financial Support on the Development of Cultural Industry_An Empirical Analysis Based on Provincial Panel Data, Social Sciences in Hunan, vol.5, pp. 116-120, 2014.

[7] Wang Renzhen, An Analysis of the Spatial Impact of Cultural Industry Development Supported by China's Provincial Finance, Journal of Jiangxi University of Finance and Economics, vol. 1, pp.3-11, 2015. 